Check for updates

Cite this: Mater. Adv., 2021, 2, 4659

Received 23rd April 2021 Accepted 3rd June 2021

DOI: $10.1039 / \mathrm{d} 1 \mathrm{ma} 00376 \mathrm{c}$

rsc.li/materials-advances

\title{
Flexible electrochromic devices prepared on ultra-thin ITO glass $\dagger$
}

\author{
Marco Schott, (D) * Lukas Niklaus, (D) Christine Müller, Begüm Bozkaya (D) and \\ Guinevere A. Giffin (D)
}

\begin{abstract}
Electrochromic devices (ECDs) containing iron-based metallo-supramolecular polymers (Fe-MEPE) and Prussian blue (PB) as active electrode materials, a polymer electrolyte and flexible ultra-thin indium tin oxide (ITO) glass as transparent conductive substrate are demonstrated here. The electrochromic Fe-MEPE and PB thin films were deposited on ultra-thin ITO glass by means of dip coating and electrodeposition, respectively, and characterized optically and (spectro-)electrochemically. By applying a low voltage of $2.5 \mathrm{~V} /-0.5 \mathrm{~V}$, the Fe-MEPE/PB ECDs can be reversibly switched from a blue-colored dark state to a nearly colorless bright state with a visible light transmittance $\left(\tau_{v}\right)$ change from $8 \%$ to $58 \%$. The devices exhibit a fast response for decoloration/coloration and good cycling stability tested over 250 switching cycles without any substantial loss of optical contrast. Thus, these ECDs based on ultrathin glass are very attractive for flexible, lightweight, and low-power electrochromic applications, e.g., in architectural or automotive glazing, aircraft, marine, home appliances, and displays.
\end{abstract}

\section{Introduction}

Electrochromic devices (ECDs) are able to change their optical properties (light absorption/transmission, reflection) induced by an applied external electrical stimulus, such as voltage or current. Common inorganic and organic electrochromic (EC) material are metal oxides (e.g., tungsten or nickel oxide ${ }^{1-3}$ ), Prussian blue $(\mathrm{PB})^{4}$ and its analogs (PBA), ${ }^{5,6}$ viologens ${ }^{7}$ or conducting polymers. ${ }^{8,9}$ Metallo-supramolecular polymers (MEPEs), based on transition metal ions and bis(terpyridine) ligands, are a new class of hybrid EC materials that have attracted special attention due to their outstanding optoelectronic properties. ${ }^{10,11}$ Their color can be modified by changing the metal ion, ${ }^{12,13}$ ligand structure, ${ }^{14}$ counter ion, ${ }^{15}$ and $\mathrm{pH}^{16}$ leading to a broad color palette. The solution-processable MEPE can be applied as thin films on transparent conductive substrates by means of wetchemical coating methods, e.g., spin or dip coating. ${ }^{17}$ The cathodically-coloring (i.e. coloration upon reduction) Fe-MEPE used in this study consists of $\mathrm{Fe}^{2+}$ ions and 1,4-bis $\left(2,2^{\prime}: 6^{\prime}, 2^{\prime \prime}-\right.$ terpyridin- $4^{\prime}$-yl)benzene as ligand and exhibits a reversible EC effect due to the oxidation from $\mathrm{Fe}^{2+}$ (blue-violet) to $\mathrm{Fe}^{3+}$ (colorless). PB (iron(III) hexacyanoferrate(II), $\mathrm{Fe}_{4}\left[\mathrm{Fe}(\mathrm{CN})_{6}\right]_{3}$ ) is a prominent anodically-coloring (i.e. coloration upon oxidation) EC material that switches complimentary to Fe-MEPE from blue $\left(\mathrm{Fe}^{2+/ 3+}\right)$ to colorless $\left(\mathrm{Fe}^{2+/ 2+}\right) \cdot{ }^{18}$ Therefore, $\mathrm{PB}$ is suitable as

Fraunhofer Institute for Silicate Research ISC, Neunerplatz 2, Würzburg 97082, Germany. E-mail: marco.schott@isc.fraunhofer.de

$\dagger$ Electronic supplementary information (ESI) available. See DOI: 10.1039/d1ma00376c counter electrode for MEPE-based ECDs. ${ }^{19}$ Moreover, it can also be applied via wet-chemical deposition. ${ }^{20}$ The demand for polymeric or organometallic EC materials has been notably increasing in recent years due to their potential applications in next generation flexible, lightweight ECDs with high optical contrast, fast response times and low power consumption. ${ }^{20-22}$ The design and fabrication of flexible, stretchable and foldable ECDs with integrated deformable electronics are of high interest for divers EC applications, such as adaptive camouflage, biometric devices, robotic skin, wearable displays, and fashion. ${ }^{23}$ A typical flexible ECD consists of PET-based, transparent conductive substrates, an EC and ion storage layer, and an ion conductive polymer electrolyte. $^{24,25}$

As an alternative to soft polymer-based substrates ultra-thin glass has been gained attention in recent years for various applications such as organic light emitting diodes (OLEDs), ${ }^{26}$ electrowetting devices, ${ }^{27}$ smart windows, ${ }^{28,29}$ and solar cells. ${ }^{30,31}$ A few studies of ITO-coated ultra-thin and flexible glass for the aforementioned applications have been conducted. CastroHermosa et al. developed flexible perovskite solar cells on ultra-thin ITO glass via roll-to-roll sputtering processes for indoor power generators. ${ }^{31} \mathrm{Kim}$ et al. investigated flexible and semi-transparent $\mathrm{Cu}\left(\mathrm{In}_{1-x}, \mathrm{Ga}_{x}\right) \mathrm{Se}_{2}$ (CIGSe) solar cells prepared on ultra-thin glass for their use in bifacial photovoltaics. ${ }^{30}$ In comparison to commercially available ITO glass or PET-based transparent conductive substrates, ultra-thin ITO glass provides good optical properties with an average visible light transmittance $\left(\tau_{\mathrm{v}}\right)$ of $81.2 \%$, while possessing a sheet resistance of $13 \Omega \mathrm{sq}^{-1}$ and 1600 bending cycles at $20.5 \mathrm{~mm}$ curvature. ${ }^{30}$ Fahland et al. 


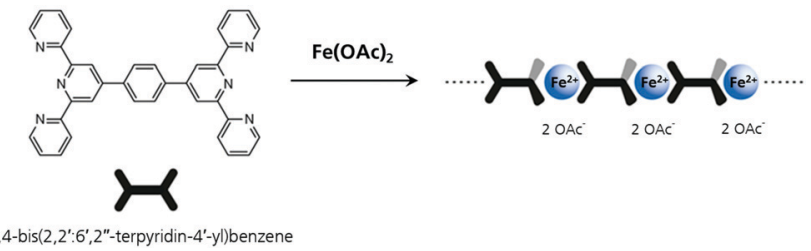

Scheme 1 Chemical structure of Fe-MEPE synthesized by $1: 1$ complexation of the bis(terpyridine) ligand 1,4-bis(2,2': $6^{\prime}, 2^{\prime \prime}$-terpyridin- $4^{\prime}$-yl) benzene and $\mathrm{Fe}(I)$ acetate.

presented a cost-effective roll-to-roll ITO deposition onto ultra-thin glass $(100 \mu \mathrm{m})$ in a specially developed coating equipment. ${ }^{32}$ During the deposition, the substrate was heated and the optical properties of ITO were examined by resistivity, optical, and XRD measurements. At a temperature of $190{ }^{\circ} \mathrm{C}$, samples with minimal roughness could be prepared. The lowest sheet resistance as well as the resistivity of the layers were obtained at a substrate temperature of $310{ }^{\circ} \mathrm{C}$ during ITO deposition as $12 \Omega \mathrm{sq}^{-1}$ and $1.5 \times 10^{-4} \Omega \mathrm{cm}^{-1}$, correspondingly. Sung et al. demonstrated an anti-reflective (AR) coating with a conductive ITO layer on ultra-thin $(100 \mu \mathrm{m})$ glass substrates, which can be used for the fabrication of solar cells, displays or antennas..$^{33}$ The coating layers included ITO providing a conductivity of $2.95 \times 10^{5} \mathrm{~S} \mathrm{~m}^{-1}$ and $\mathrm{AlSiO}_{2}$. This coating was stable upon 10000 bending cycles and exhibited no delamination.

In this work, novel ECDs containing Fe-MEPE and PB as complementary switching electrode materials and a proprietary electrolyte were fabricated for the first time on ultra-thin ITO glass. Their overall EC performance was compared to reference ECDs based on fluorine-doped tin oxide (FTO) glass and PET-ITO as transparent conductive substrates, in particular with regard to the optical properties, response time, and cycling stability. The results presented here offer new possibilities for flexible, lightweight and low-power ECDs that should be of interest for various optoelectronic applications.

\section{Experimental}

All chemicals were purchased from Sigma-Aldrich and used without further purification. FTO glass (TEC $\left.{ }^{\mathrm{TM}} 15\right)$ and PET-ITO films (OC50) were purchased from Pilkington and Eastman Chemical Company, respectively. The ultra-thin ITO glass substrates (SCHOTT AF32 ${ }^{\mathbb{R}}$ ) with a thickness of $100 \mu \mathrm{m}$ were provided by Fraunhofer FEP. The transparent conductive ITO (indium tin oxide) layer was deposited onto ultra-thin glass by using roll-to-roll (R2R) sputtering. ${ }^{29}$ Sheet resistance $\left[\Omega \mathrm{sq}^{-1}\right]$ was measured with a 4-point conductivity meter from Jandel (HM21 Test Unit).

\section{Fe-MEPE and PB films on ultra-thin ITO glass}

Fe-MEPE was synthesized via self-assembly of the bis(terpyridine) ligand 1,4-bis(2,2': 6',2'-terpyridin-4'-yl)benzene and $\mathrm{Fe}(\mathrm{II})$ acetate with a metal ion-to-ligand molar ratio of $1: 1$ (Scheme 1) according to the procedure described in ref. 17 and 34 .

For the dip-coating process, a Fe-MEPE solution $(28 \mathrm{mM}$ in methanol/ethanol/2-butoxyethanol) containing a proprietary polyurethane-polysiloxane binder to improve the film-forming properties, adhesion, and thermal stability was used. The Fe-MEPE thin films were deposited by a withdrawal speed of $100 \mathrm{~mm} \mathrm{~min}^{-1}$. After the dip coating process, the Fe-MEPE electrodes were annealed at $60{ }^{\circ} \mathrm{C}$ for $24 \mathrm{~h}$.

The $\mathrm{PB}\left(\mathrm{Fe}_{4}\left[\mathrm{Fe}(\mathrm{CN})_{6}\right]_{3}\right)$ thin films were electrodeposited from an aqueous electrolyte containing potassium hexacyanoferrate(III) $\left(\mathrm{K}_{3} \mathrm{Fe}(\mathrm{CN})_{6}\right)$, and iron(III) chloride $\left(\mathrm{FeCl}_{3}\right) .^{35,36}$ By using a PGU 20V-5A-E potentiostat/galvanostat, a current density of $25 \mu \mathrm{A} \mathrm{cm}^{-2}$ was applied for $200 \mathrm{~s}$ resulting in a PB layer with a nominal charge density of $5.0 \mathrm{mC} \mathrm{cm}^{-2}$. Finally, the PB electrodes were annealed at $100{ }^{\circ} \mathrm{C}$ for $20 \mathrm{~min}$.

\section{Fabrication of electrochromic devices (ECDs)}

The ECDs with the cell configuration [transparent conductive oxide (TCO) substrate/Fe-MEPE/electrolyte/PB/TCO substrate] were fabricated with an active (switchable) area of $3.5 \times 3.5 \mathrm{~cm}^{2}$. The ECDs were assembled with a proprietary $\mathrm{LiClO}_{4}{ }^{-}$ containig gel electrolyte $\left(\mathrm{LiClO}_{4} / \mathrm{PC} / \mathrm{DEC} /\right.$ Paraloid) under argon atmosphere in a glove box according to the procedure previously described in ref. 1 The ECDs with FTO glass, PET-ITO, and ultra-thin ITO glass are referred to as ECD-1, ECD-2, and ECD-3, respectively.

\section{Optical, spectroelectrochemical and electrochemical characterization}

UV/Vis spectra and color coordinates according to the CIELab color space ( $L^{*}=$ lightness, $a^{*}=$ green-red, $b^{*}=$ blue-yellow) were recorded using an Avantes AvaSpec-2048 standard fiber-optic spectrometer equipped with a balanced deuterium-halogen light source.

In situ spectroelectrochemical measurements of the Fe-MEPE and PB electrodes were carried out under an argon atmosphere (glovebox) at room temperature in a quartz cell with $1 \mathrm{M} \mathrm{LiClO}_{4} /$ PC as electrolyte and Li as counter and reference electrodes, respectively.

A Solartron Multistat 1470E multi-channel potentiostat/ galvanostat was used for electrochemical characterization (cyclic voltammetry, charging/discharging and cycling stability measurements) of the EC electrodes and the ECDs. For the measurements of the EC electrode materials, a three-electrode set-up with Fe-MEPE- and PB on ultra-thin ITO glass as working electrodes (active area: $1 \times 1 \mathrm{~cm}^{2}$ ), Li as counter and reference electrodes, and $1 \mathrm{M} \mathrm{LiClO}_{4} / \mathrm{PC}$ as electrolyte under an argon atmosphere (glovebox) at room temperature was used.

The spectroelectrochemical measurements of the ECDs (incl. UV-Vis and $L^{*} a^{*} b^{*}$ color coordinates according to CIELAB color space of the dark and bright state) were performed in situ during device operation. The optimal voltages for decoloration/ coloration of the ECDs were determined by stepwise increasing/ decreasing the cell voltage until no further transmittance changes were observed at higher/lower voltages. The $\tau_{\mathrm{v}}$ values were calculated according to DIN EN410. The electrochemical characterization (potentiostatic cycling) of the ECDs was performed with a Solartron Multistat 1470E potentiostat/ galvanostat. 


\section{Results and discussion}

The ITO-coated ultra-thin glass with a thickness of $100 \mu \mathrm{m}$ exhibits excellent properties for the application in flexible and lightweight ECDs. In comparison to commonly used TCO substrates, such as FTO glass or PET-ITO, ultra-thin ITO glass shows higher visible light transmittance $\left(\tau_{\mathrm{v}}=88 \%\right)$ and lower haze values $(>0.1 \%)$, as can be seen in the transmissions spectra in Fig. 1. Additionally, the sheet resistance of approx. $23 \Omega \mathrm{sq}^{-1}$ and, thus, the high conductivity could decrease the response time of the final ECDs. Due to the high UV and thermal stability of glass, these substrates are interesting also for the deposition of inorganic EC materials (e.g. tungsten or nickel oxides), which are usually deposited by high-temperature sputtering processes.

The optical data of the TCO substrates are summarized in Table 1.

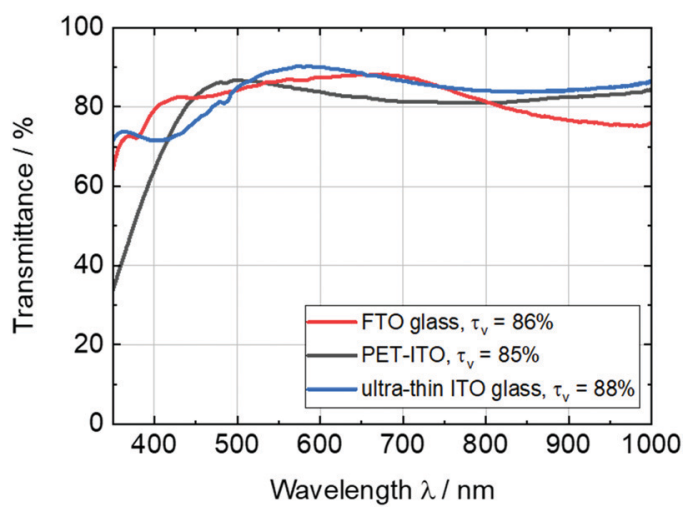

Fig. 1 Comparison of transmittance spectra of commercially available FTO glass (thickness: $4 \mathrm{~mm})$ and PET-ITO films $(127 \mu \mathrm{m})$, and ultra-thin ITO glass $(100 \mu \mathrm{m})$.
Characterization of Fe-MEPE and PB ultra-thin glass electrodes

As the EC characteristics of Fe-MEPE and PB on FTO glass and PET-ITO were already demonstrated in previous studies, ${ }^{1,25}$ only a detailed investigation of Fe-MEPE and PB thin films on ultra-thin ITO glass is described here. The film thickness and surface morphology of the Fe-MEPE and PB electrodes were characterized by scanning electron microscopy (SEM) as shown in Fig. 2. The cross-section images show the smooth Fe-MEPE and PB layer with a film thickness of approx. $700 \mathrm{~nm}$ and $115 \mathrm{~nm}$, respectively, on the highly uniform ITO layer $(\sim 150 \mathrm{~nm})$ with well-defined interfaces. Therefore, the adhesion of the EC thin films on ITO is very good. The top-view images of the Fe-MEPE and PB surface are shown in Fig. S1 (ESI $\dagger$ ).

The optical characterization of the Fe-MEPE and PB thin films on ultra-thin ITO glass are shown in Fig. S2 (ESI $\dagger$ ) and the results are briefly summarized in Table S1 (ESI $\dagger$ ). For Fe-MEPE, two significant peaks are visible in the spectrum: the d-d transition at $388 \mathrm{~nm}$ and the characteristic metal-to-ligand charge transfer (MLCT) transition at $593 \mathrm{~nm}$ resulting in an intense blue-violet hue. The intensity of the MLCT peak increases with the Fe-MEPE film thickness and can be controlled by the concentration of the coating solution and/or the withdrawal speed. In contrast, the light blue-colored PB thin films exhibit a broad intervalence charge transfer (IVCT) band at around $700 \mathrm{~nm}$ arising from a short range exchange interaction through the cyano bridge between the two iron centers $\left(\mathrm{Fe}^{2+}\right.$ and $\left.\mathrm{Fe}^{3+}\right) .{ }^{37}$ The thickness (charge density) of the electrodeposited PB layers can be adjusted by the current density and the deposition time.

Fig. 3 shows the spectroelectrochemical measurements of Fe-MEPE and PB thin films on ultra-thin ITO glass. Fe-MEPE as a cathodically-coloring EC material shows a reversible color change between blue-violet (reduced state, $\mathrm{Fe}^{2+}$ ) at $3.2 \mathrm{~V}$ vs. $\mathrm{Li} / \mathrm{Li}^{+}$and virtually colorless (oxidized state, $\mathrm{Fe}^{3+}$ ) at $4.4 \mathrm{~V}$ vs. $\mathrm{Li}^{2} \mathrm{Li}^{+}$, whereas $\mathrm{PB}$ as an complementary switching (anodically-coloring) EC

Table 1 Color $\left(L^{*} a^{*} b^{\star}\right)$ coordinates, visible light transmittance $\left(\tau_{\mathrm{v}}\right)$, sheet resistance, haze and total thickness of various TCO substrates

\begin{tabular}{|c|c|c|c|c|c|c|c|c|}
\hline Substrate & Supplier & $L^{*}$ & $a^{*}$ & $b^{*}$ & $\tau_{\mathrm{v}} / \%$ & Sheet resistance $/ \Omega \mathrm{sq}^{-1}$ & Haze/\% & Thickness \\
\hline FTO glass & Pilkington & 94.3 & 0.2 & 2.6 & 86 & 14 & 0.6 & $4 \mathrm{~mm}$ \\
\hline PET-ITO & Eastman & 93.7 & -2.9 & 2.9 & 85 & 50 & 1.0 & $127 \mu \mathrm{m}$ \\
\hline Ultra-thin ITO glass & Fraunhofer FEP & 94.9 & -1.3 & 8.1 & 88 & 23 & 0.1 & $100 \mu \mathrm{m}$ \\
\hline
\end{tabular}
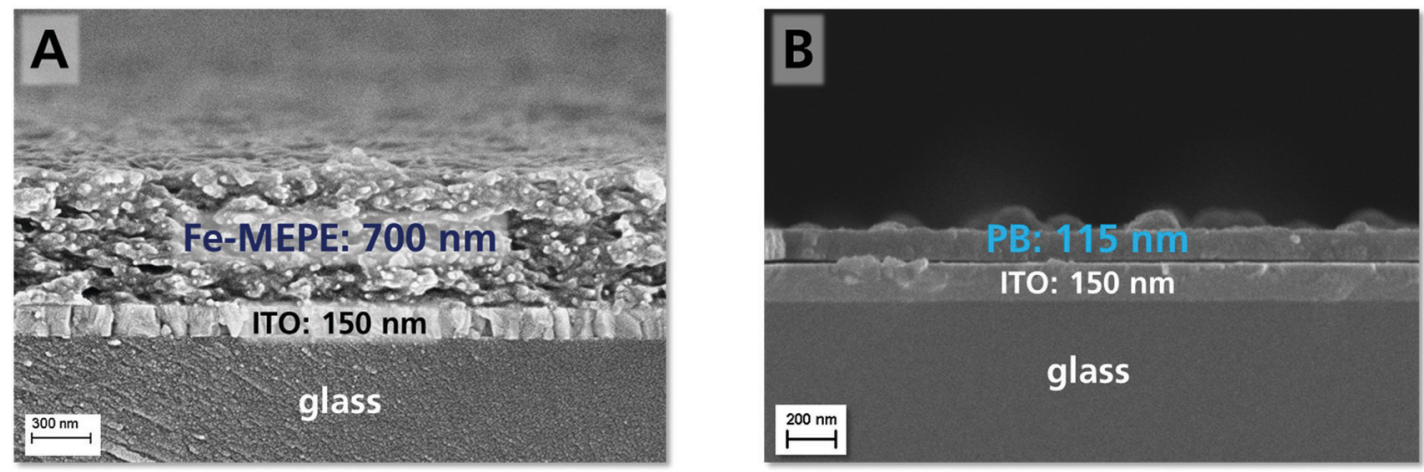

Fig. 2 SEM cross-section images depicting the thickness and interfaces of the (A) Fe-MEPE and (B) PB layer on ultra-thin ITO glass. 

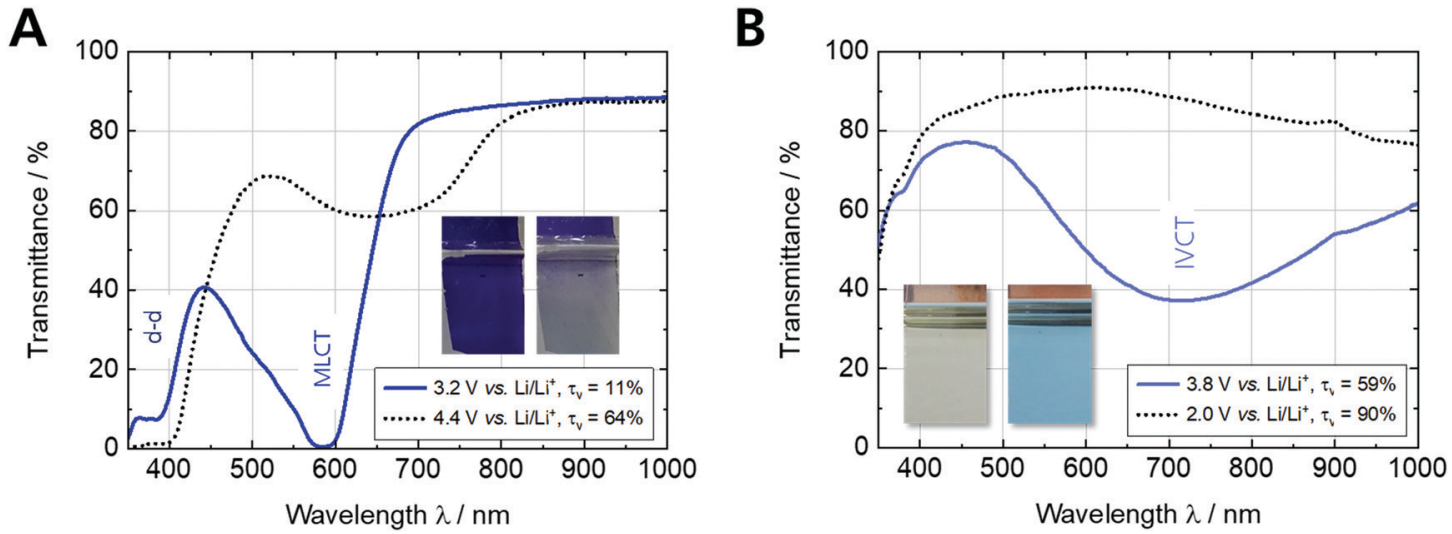

Fig. 3 Spectroelectrochemical characterization of (A) Fe-MEPE and (B) PB thin film electrodes with Li as counter and reference electrode in $1 \mathrm{M}$ LiClO ${ }_{4} /$ PC as electrolyte.

Table 2 Color $\left(L^{*} a^{*} b^{*}\right)$ coordinates, transmittance in the colored $\left(T_{\mathrm{c}}\right)$ and bright state $\left(T_{\mathrm{b}}\right)$ at $\lambda_{\max }$ visible light transmittance $\left(\tau_{\mathrm{v}}\right)$, charge density $(q)$, and coloration efficiency $(\eta)$ of the EC electrodes (Fe-MEPE and PB)

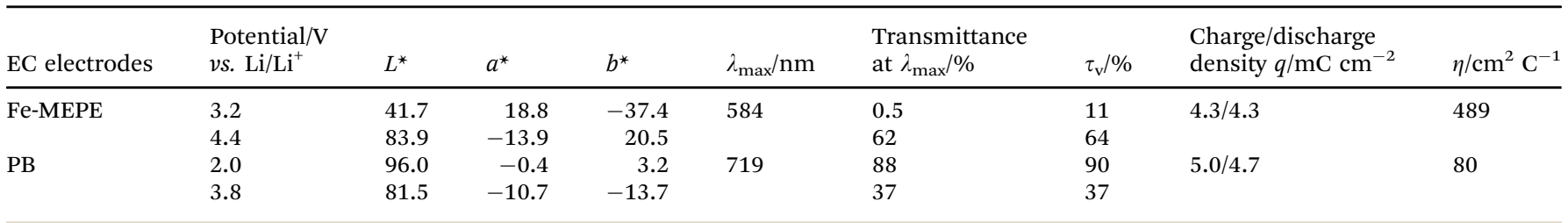

material switches from light blue (oxidized mixed- valence state, $\mathrm{Fe}^{2+/ 3+}$ ) at $3.8 \mathrm{~V}$ vs. $\mathrm{Li} / \mathrm{Li}^{+}$to completely colorless (reduced state, $\mathrm{Fe}^{2+/ 2+}$ ) at $2.0 \mathrm{~V}$ vs. $\mathrm{Li} / \mathrm{Li}^{+}$(Fig. $3 \mathrm{~B}$ ).

Therefore, these two electrode materials are suitable to be combined in an ECD. The maxima of the MLCT and IVCT transitions of Fe-MEPE and PB are shifted towards $584 \mathrm{~nm}$ and $719 \mathrm{~nm}$, respectively, when the electrodes are immersed in the liquid electrolyte. The EC properties of the Fe-MEPE and PB thin film electrodes as well as the Fe-MEPE/PB ECD are summarized in Table 2.

In addition to the spectroelectrochemical characterization, the Fe-MEPE and PB electrodes were characterized by standard electrochemical methods including cyclic voltammetry (Fig. 4) and charging/discharging over the course of 1000 switching

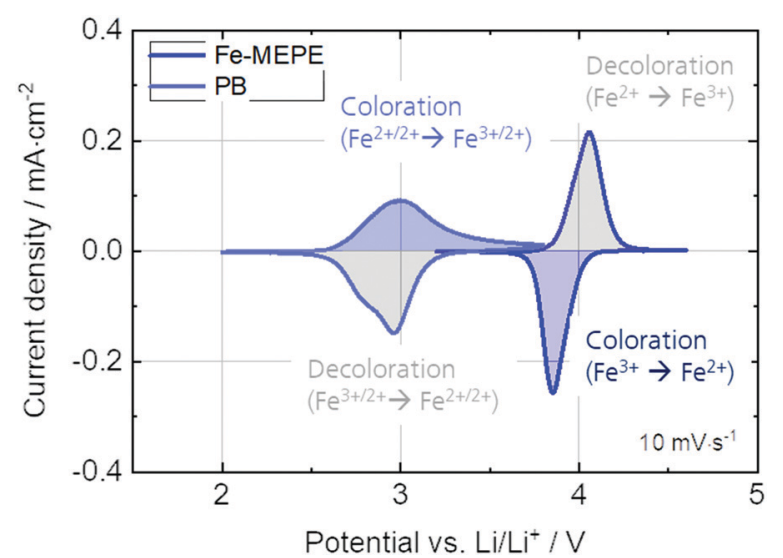

Fig. 4 Cyclic voltammograms (at $10 \mathrm{mV} \mathrm{s}^{-1}$ ) of the Fe-MEPE and PB thin film electrodes with $\mathrm{Li}$ as counter and reference electrode in $1 \mathrm{M}$ $\mathrm{LiClO}_{4} / \mathrm{PC}$ as electrolyte. cycles (Fig. 5). In addition, Fig. S3 (ESI $\dagger$ ) shows the linear dependency of the anodic and cathodic peak current densities $v s$. the square root of the scan rate.

The cyclic voltammetry and charging/discharging measurements of the Fe-MEPE electrodes confirm the high reversibility of the decoloration (oxidation) and coloration (reduction) processes. The maximum areal charge density for decoloration/coloration of Fe-MEPE was determined by integrating the area of the anodic and cathodic curves to be around $4.3 \mathrm{mC} \mathrm{cm}^{-2}$ at a scan rate of $10 \mathrm{mV} \mathrm{s}^{-1}$. At a current density of $50 \mu \mathrm{A} \mathrm{cm} \mathrm{cm}^{-2}$, the Coulomb efficiency (= ratio of the discharge to charge density) is higher than $99 \%$ as depicted in Fig. 5. For the application of Fe-MEPEbased ECDs, e.g., in commercial smart windows, long-term cycling stability is necessary. After 1000 charging/discharging steps between 3.2 and $4.4 \mathrm{~V}$ vs. $\mathrm{Li} / \mathrm{Li}^{+}$, the Fe-MEPE thin film electrodes show a charge retention of more than $97 \%(3.97 \rightarrow$ $3.88 \mathrm{mC} \mathrm{cm}^{-2}$ ), indicating a remarkably stable switching behavior under inert conditions (glovebox) at room temperature. A similar procedure was performed for the electrochemical evaluation of the PB electrode, where the maximum charge density during decoloration/coloration at $10 \mathrm{mV} \mathrm{s}^{-1}$ was calculated to be 5.0 and $4.7 \mathrm{mC} \mathrm{cm}^{-2}$, respectively. At current densities of $50 \mu \mathrm{A} \mathrm{cm}^{-2}$, the Coulomb efficiency is higher than $92 \%$ with a charge retention after 1000 charging/discharging steps between 2.0 and $3.8 \mathrm{~V} v$ s. $\mathrm{Li} / \mathrm{Li}^{+}$of more than $93 \%\left(4.25 \rightarrow 3.98 \mathrm{mC} \mathrm{cm}^{-2}\right)$.

\section{Fe-MEPE/PB ECDs on ultra-thin ITO glass in comparison to ECDs on FTO glass or PET-ITO}

The use of ultra-thin ITO glass for ECDs is demonstrated with Fe-MEPE and PB as the working and counter electrodes, 

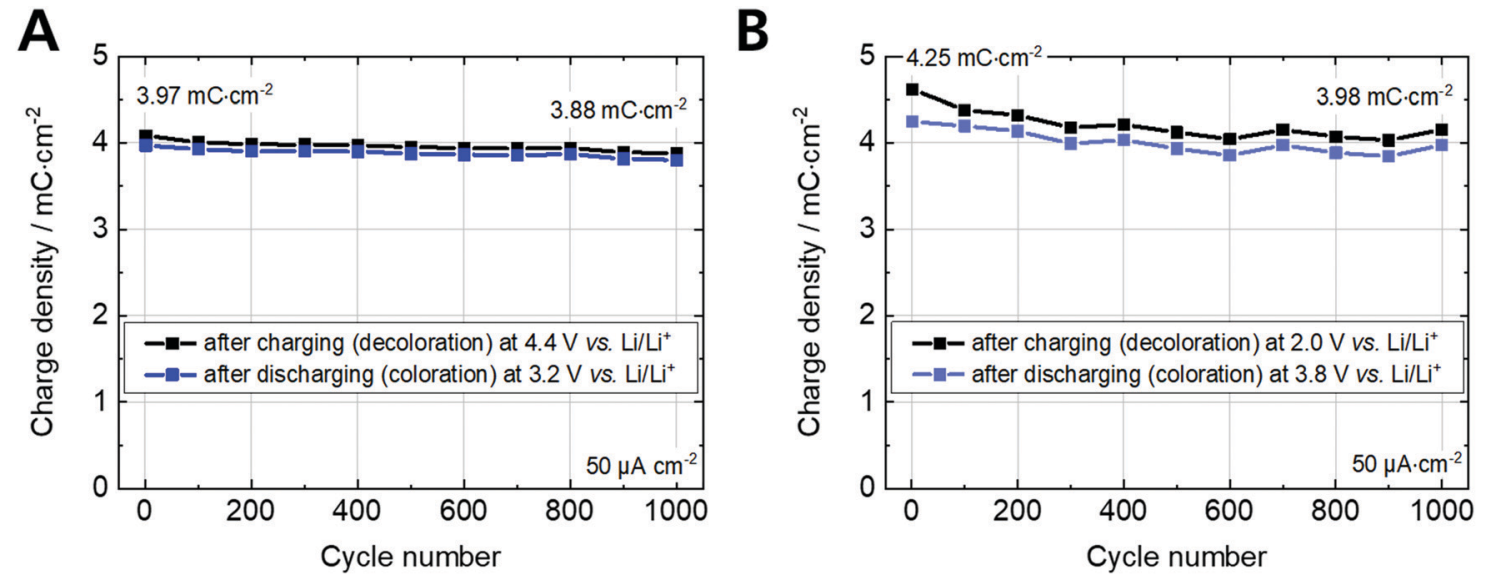

Fig. 5 Galvanostatic charging/discharging measurements with a current density of $50 \mu \mathrm{A} \mathrm{cm}{ }^{-2}$ over 1000 switching cycles of (A) Fe-MEPE and (B) PB thin film electrodes on ultra-thin glass with $\mathrm{Li}$ as counter and reference electrode in $1 \mathrm{M} \mathrm{LiClO}_{4} / \mathrm{PC}$ as electrolyte.

respectively. The nominal charge density of the PB electrode $\left(q=5 \mathrm{mC} \mathrm{cm}^{-2}\right)$ was adapted to the Fe-MEPE electrode $\left(q=4.3 \mathrm{mC} \mathrm{cm}^{-2}\right)$ to reach the maximum optical contrast in the ECDs. The three ECDs (Fe-MEPE/PB) containing a proprietary gel electrolyte were characterized by standard spectroelectrochemical and electrochemical methods as shown in Fig. 6. Fig. $6 \mathrm{~A}$ and $\mathrm{C}$ depicts the transmittance spectra of the two reference cells based on FTO glass (ECD-1) and PET-ITO (ECD-2). The Fe-MEPE/PB ECDs are deep blue-colored in their dark state at cell voltages of $-0.5 \mathrm{~V}$ due to the distinct MLCT band of Fe-MEPE at $\lambda_{\max }=584 \mathrm{~nm}$ and switch reversibly to a virtually colorless state at $2.5 \mathrm{~V}$. ECD-1 and ECD-2 switch between $\tau_{\mathrm{v}}$ values [\%] of 7/62 and 10/64 in the dark/bright state. The transmittance spectra of ECD-3 (ultra-thin glass) in Fig. 6E show an overall change of the $\tau_{\mathrm{v}}$ value from $8 \%$ (dark) to $58 \%$ (bright). In Table 3 the color coordinates and $\tau_{\mathrm{v}}$ values of the three ECD configurations are summarized. In addition to the spectroelectrochemical measurements, the ECDs were characterized by standard electrochemical methods including cyclic voltammetry (Fig. S4, ESI $\dagger$ ) and potentiostatic cycling over the course of 250 switching cycles (Fig. 6B, D and F). The cyclic voltammograms of all three ECDs show reversible redox peaks at cell voltages of approx. $1.2 \mathrm{~V}$ (decoloration) and $0.8 \mathrm{~V}$ (coloration). Moreover, the study of the scan-rate-dependent (1-20 $\left.\mathrm{mV} \mathrm{s}^{-1}\right)$ CVs indicated that the peak current densities of the decoloration and coloration processes were linearly proportional to the square root of the scan rate (Fig. S5, ESI $\dagger$ ).

The response time ( $=$ time to reach $10 \%$ of initial current density) of the ECDs was determined from the current densitytime profile shown in Fig. S6 (ESI $\dagger$ ). For ECD-3 on ultra-thin glass, values of $8 \mathrm{~s}$ and $4 \mathrm{~s}$ were obtained for decoloration and coloration, respectively. These values are in between those for ECD-1 $(1 \mathrm{~s} / 2 \mathrm{~s})$ and ECD-2 $(6 \mathrm{~s} / 8 \mathrm{~s})$ and in accordance with the sheet resistance of the various TCO substrates: FTO glass < ultra-thin ITO glass < PET-ITO (Table 1).

Long-term cycling stability is required for most commercial EC applications. Therefore, Fig. 6B, D and F demonstrate the stable cycling of the ECDs on various TCO substrates over the course of 250 switching cycles at room temperature with lower and upper cut-off voltages of $-0.5 \mathrm{~V}$ and $2.5 \mathrm{~V}$, respectively. The transmittance change at $584 \mathrm{~nm}$ (maximum MLCT transition) remains relatively constant for all three ECDs with a slight decrease in the bright state from $57 \%$ to $54 \%$ (ECD-1), $60 \%$ to $59 \%$ (ECD-2), and $51 \%$ to $45 \%$ (ECD-3), respectively, while maintaining the initial dark state $\left(T_{\mathrm{c}}<0.5 \%\right)$. This is evident from the transmittance spectra for the $1^{\text {st }}$ and $250^{\text {th }}$ cycle (Fig. S7A, C and E, ESI $\dagger$ ). Furthermore, the stability is reflected in the change of the $\tau_{\mathrm{v}}$ values [\%] from $8 / 60 \rightarrow 9 / 56,9 / 64 \rightarrow 10 / 63$, and $8 / 58 \rightarrow 54 / 8$ in the dark/bright state for ECD-1, ECD-2, and ECD-3, respectively (Fig. S7B, D and F, ESI $\dagger$ ).

\section{Conclusion}

Novel ECDs based on complementary-switching Fe-MEPE and PB thin films on flexible ultra-thin $(100 \mu \mathrm{m})$ ITO glass substrates have been fabricated and their electrochromic performance demonstrated for the first time. The optical, electrochemical and spectroelectrochemical properties of the dip-coated Fe-MEPE and electrodeposited PB thin film electrodes were investigated in detail. Both materials show excellent EC properties in terms of optical contrast, coloration efficiency, response time and cycling stability. The ultra-thin ITO glass combines the flexibility of plastic substrates with the high optical quality and robustness of glass, such as high heat resistance, that makes this substrate also applicable for high-temperature deposition of other EC materials (e.g. metal oxides). Furthermore, ultra-thin glass can be processed by continuous and large-scale roll-to-roll coating methods as an alternative to the commonly used PET-based ITO substrates. The proof-of-concept Fe-MEPE/PB cell configuration on ultra-thin ITO glass with a visible light transmittance change from $8 \%$ (at $0 \mathrm{~V}$ ) to $58 \%$ (at $2.5 \mathrm{~V}$ ) and a good cycling stability is highly promising for flexible, lightweight, and low-power ECDs in the future. The optical and EC properties of these ultra-thin glass ECDs are well comparable to ECDs prepared on FTO glass 
A

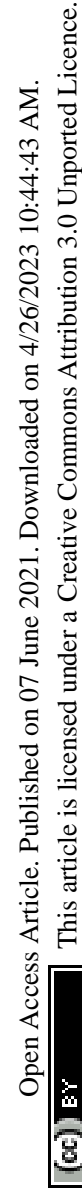

E
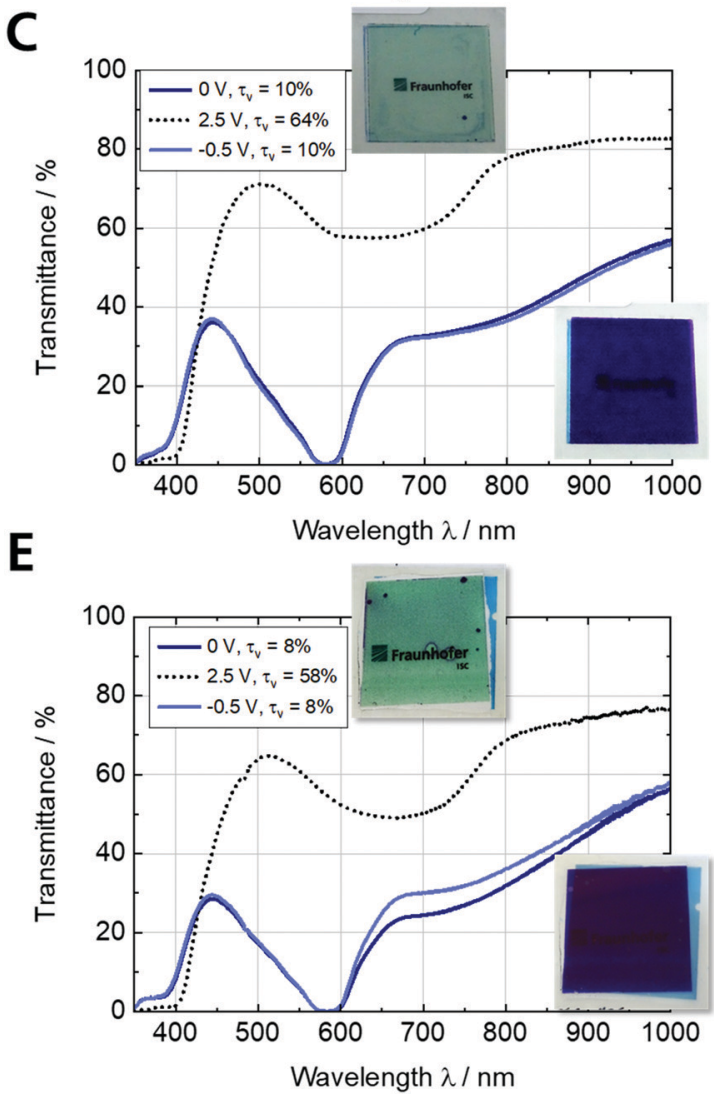

B

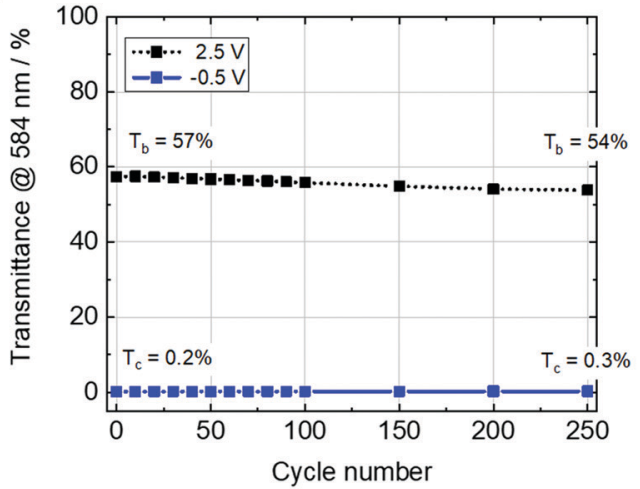

D

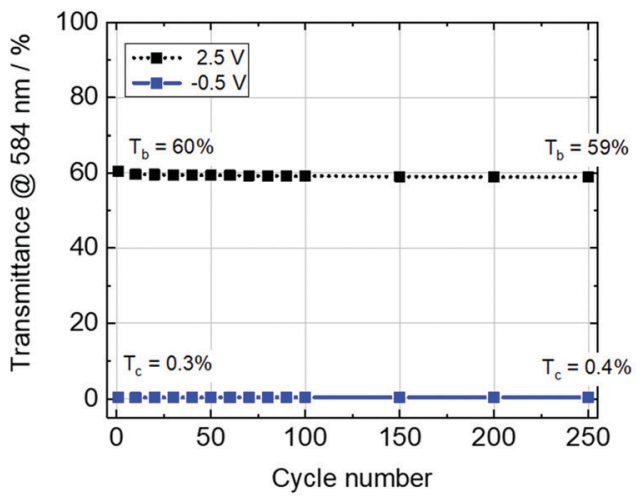

$\mathbf{F}$

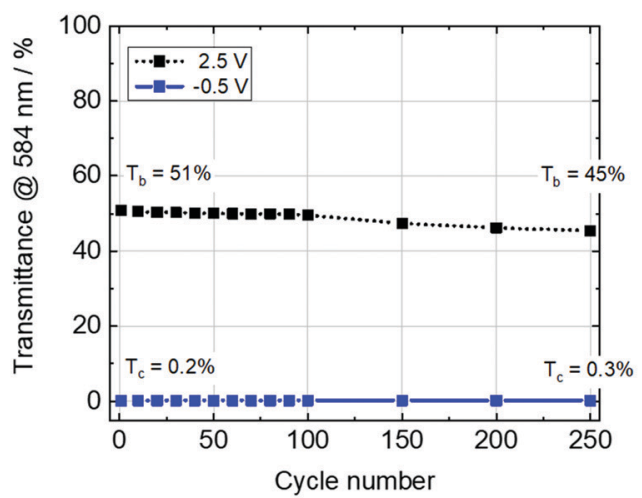

Fig. 6 Spectroelectrochemical characterization and change in transmittance at $584 \mathrm{~nm}$ over 250 potentiostatic cycles of the Fe-MEPE/PB ECDs (active area: $3.5 \times 3.5 \mathrm{~cm}^{2}$ ) on (A and B) FTO glass, (C and D) PET-ITO, and (E and F) ultra-thin ITO glass.

Table 3 Comparison of the color $\left(L^{*} a^{*} b^{\star}\right)$ coordinates, transmittance in the colored $\left(T_{c}\right)$ and bright state $\left(T_{b}\right)$ at $\lambda_{\max }=584 \mathrm{~nm}$, visible light transmittance $\left(\tau_{\mathrm{v}}\right)$, and response time of the full devices (Fe-MEPE/PB)

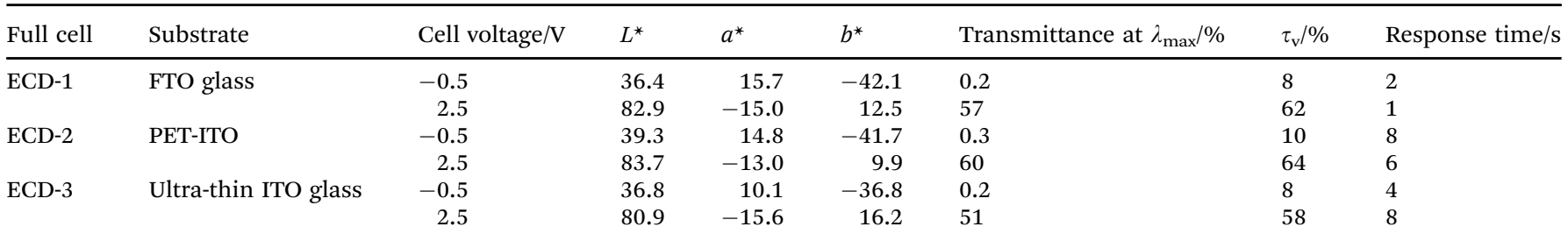

and PET-ITO substrates. Thus, these types of ECDs will be further investigated, particularly under real use conditions, to qualify them for next generation EC applications, e.g., in architectural or automotive glazing, aircraft, marine, home appliances, and displays. 


\section{Author contributions}

Marco Schott: conceptualization, supervision, writing - review \& editing, project administration. Lukas Niklaus: investigation, validation, visualization, writing - original draft preparation. Christine Müller: ECD preparation, investigation. Begüm Bozkaya: writing - original draft preparation. Guinevere A. Giffin: supervision, writing - review \& editing.

\section{Conflicts of interest}

There are no conflicts to declare.

\section{Acknowledgements}

The authors acknowledge the financial support from the Bavarian Ministry of Economic Affairs and Media, Energy and Technology for funding the Fraunhofer R\&D Center for Electromobility (grant no. 43-6629/86). Furthermore, we would like to thank Dr. Manuela Junghähnel and Jasper Westphalen (Fraunhofer FEP) for providing the ultra-thin ITO glass sheets and Werner Stracke (Fraunhofer ISC) for SEM measurements.

\section{References}

1 L. Niklaus, M. Schott, M. Mihelčič, I. Jerman, U. Posset and G. Sextl, Metallopolymers and non-stoichiometric nickel oxide: towards neutral tint large-area electrochromic devices, Sol. Energy Mater. Sol. Cells, 2019, 200, 110002.

2 C. G. Granqvist, Electrochromics for smart windows: oxidebased thin films and devices, Thin Solid Films, 2014, 564, $1-38$.

3 G. A. Niklasson and C. G. Granqvist, Electrochromics for smart windows: thin films of tungsten oxide and nickel oxide, and devices based on these, J. Mater. Chem., 2007, 17, 127-156.

4 A. Paolella, C. Faure, V. Timoshevskii, S. Marras, G. Bertoni, A. Guerfi, A. Vijh, M. Armand and K. Zaghib, A review on hexacyanoferrate-based materials for energy storage and smart windows: challenges and perspectives, J. Mater. Chem. A, 2017, 5, 18919-18932.

5 Y. Matos-Peralta and M. Antuch, Review-Prussian Blue and Its Analogs as Appealing Materials for Electrochemical Sensing and Biosensing, J. Electrochem. Soc., 2019, 167, 37510.

6 T.-C. Liao, W.-H. Chen, H.-Y. Liao and L.-C. Chen, Multicolor electrochromic thin films and devices based on the Prussian blue family nanoparticles, Sol. Energy Mater. Sol. Cells, 2016, 145, 26-34.

7 R. J. Mortimer, D. R. Rosseinsky and P. M. S. Monk, Electrochromic Materials and Devices, Wiley, 2015, pp. 57-90.

8 R. J. Mortimer, Electrochromic materials, Annu. Rev. Mater. Res., 2011, 41, 241-268.

9 P. R. Somani and S. Radhakrishnan, Electrochromic materials and devices: present and future, Mater. Chem. Phys., 2002, 77, 117-133.
10 A. M. C. Thompson, The synthesis of $2,2^{\prime}: 6^{\prime}, 2^{\prime \prime}$-terpyridine ligands-versatile building blocks for supramolecular chemistry, Coord. Chem. Rev., 1997, 160, 1-52.

11 U. S. Schubert, A. Winter and G. R. Newkome, Terpyridinebased materials, Catalytic, Optoelectronic Life Science Applications, 2011, pp. 459-505.

12 S. Pai, M. Schott, L. Niklaus, U. Posset and D. G. Kurth, A study of the effect of pyridine linkers on the viscosity and electrochromic properties of metallo-supramolecular coordination polymers, J. Mater. Chem. C, 2018, 6, 3310-3321.

13 F. S. Han, M. Higuchi and D. G. Kurth, Metallo-Supramolecular Polymers Based on Functionalized Bis-terpyridines as Novel Electrochromic Materials, Adv. Mater., 2007, 19, 3928-3931.

14 M. Schott, L. Niklaus, J. Clade and U. Posset, Electrochromic metallo-supramolecular polymers showing visible and nearinfrared light transmittance modulation, Sol. Energy Mater. Sol. Cells, 2019, 200, 110001.

15 J. Zhang, C.-Y. Hsu and M. Higuchi, Anion Effects to Electrochromic Properties of Ru-based Metallo-supramolecular Polymers, J. Photopolym. Sci. Technol., 2014, 27, 297-300.

16 C.-Y. Hsu, J. Zhang, T. Sato, S. Moriyama and M. Higuchi, Black-to-Transmissive Electrochromism with Visible-to-NearInfrared Switching of a $\mathrm{Co}(\mathrm{II})$-Based Metallo-Supramolecular Polymer for Smart Window and Digital Signage Applications, ACS Appl. Mater. Interfaces, 2015, 7(33), 18266-18272.

17 M. Schott, H. Lorrmann, W. Szczerba, M. Beck and D. G. Kurth, State-of-the-art electrochromic materials based on metallo-supramolecular polymers, Sol. Energy Mater. Sol. Cells, 2014, 126, 68-73.

18 A. Kraft, Electrochromism: a fascinating branch of electrochemistry, ChemTexts, 2019, 5, 1-18.

19 S. Mondal, T. Yoshida and M. Higuchi, Electrochromic devices using Fe(II)-based metallo-supramolecular polymer: introduction of ionic liquid as electrolyte to enhance the thermal stability, J. Soc. Inf. Disp., 2019, 27, 661-666.

20 S. Macher, M. Schott, M. Sassi, I. Facchinetti, R. Ruffo, G. Patriarca, L. Beverina, U. Posset, G. A. Giffin and P. Löbmann, New Roll-to-Roll Processable PEDOT-Based Polymer with Colorless Bleached State for Flexible Electrochromic Devices, Adv. Funct. Mater., 2020, 30, 1906254.

21 C. G. Granqvist, I. B. Pehlivan and G. A. Niklasson, Electrochromics on a roll: web-coating and lamination for smart windows, Surf. Coat. Technol., 2018, 336, 133-138.

22 H. Wang, M. Barrett, B. Duane, J. Gu and F. Zenhausern, Materials and processing of polymer-based electrochromic devices, Mater. Sci. Eng., B, 2018, 228, 167-174.

23 A. L.-S. Eh, A. W. M. Tan, X. Cheng, S. Magdassi and P. S. Lee, Recent Advances in Flexible Electrochromic Devices: prerequisites, Challenges, and Prospects, Energy Technol., 2018, 6, 33-45.

24 M. Schott, W. Szczerba, U. Posset, A. Šurca Vuk, M. Beck, H. Riesemeier, A. F. Thünemann and D. G. Kurth, In operando XAFS experiments on flexible electrochromic devices based on Fe(II)-metallo-supramolecular polyelectrolytes and vanadium oxide, Sol. Energy Mater. Sol. Cells, 2016, 147, 61-67. 
25 S. Macher, M. Rumpel, M. Schott, U. Posset, G. A. Giffin and P. Löbmann, Avoiding Voltage-Induced Degradation in PET-ITO-Based Flexible Electrochromic Devices, ACS Appl. Mater. Interfaces, 2020, 12(32), 36695-36705.

26 M. D. J. Auch, O. K. Soo, G. Ewald and C. Soo-Jin, Ultrathin glass for flexible OLED application, Thin Solid Films, 2002, 417, 47-50.

27 H. You and A. J. Steckl, Lightweight electrowetting display on ultra-thin glass substrate, J. Soc. Inf. Disp., 2013, 21, 192-197.

28 T. Bárta, J. Vlček, J. Houška, S. Haviar, R. Čerstvý, J. Szelwicka, M. Fahland and J. Fahlteich, Pulsed Magnetron Sputtering of Strongly Thermochromic $\mathrm{VO}_{2}$-Based Coatings with a Transition Temperature of $22{ }^{\circ} \mathrm{C}$ onto Ultrathin Flexible Glass, Coatings, 2020, 10, 1258.

29 C. G. Granqvist and G. A. Niklasson, Thermochromic OxideBased Thin Films and Nanoparticle Composites for EnergyEfficient Glazings, Buildings, 2017, 7, 3.

30 D. Kim, S. S. Shin, S. M. Lee, J.-S. Cho, J. H. Yun, H. S. Lee and J. H. Park, Flexible and Semi-Transparent Ultra-Thin CIGSe Solar Cells Prepared on Ultra-Thin Glass Substrate: a Key to Flexible Bifacial Photovoltaic Applications, Adv. Funct. Mater., 2020, 30, 2001775.

31 S. Castro-Hermosa, G. Lucarelli, M. Top, M. Fahland, J. Fahlteich and T. M. Brown, Perovskite Photovoltaics on Roll-To-Roll Coated Ultra-thin Glass as Flexible High-Efficiency Indoor Power Generators, Cell Rep. Phys. Sci., 2020, 100045.
32 M. Fahland, O. Zywitzki, T. Modes, K. Vondkar, T. Werner, C. Ottermann, M. Berendt and G. Pollack, Roll-to-roll sputtering of indium tin oxide layers onto ultrathin flexible glass, Thin Solid Films, 2019, 669, 56-59.

33 Y. Sung, R. E. Malay, X. Wen, C. N. Bezama, V. V. Soman, M.-H. Huang, S. M. Garner, M. D. Poliks and D. Klotzkin, Anti-reflective coating with a conductive indium tin oxide layer on flexible glass substrates, Appl. Opt., 2018, 57, 2202-2207.

34 M. Schott, M. Beck and F. Winkler, et al., Fabricating electrochromic thin films based on metallo-polymers using layer-by-layer self-assembly: an attractive laboratory experiment, J. Chem. Educ., 2015, 92, 364-367.

35 S. Duluard, A. Celik-Cochet, I. Saadeddin, A. Labouret, G. Campet, G. Schottner, U. Posset and M.-H. Delville, Electrochromic devices based on in situ polymerised EDOT and Prussian Blue: influence of transparent conducting oxide and electrolyte composition-towards up-scaling, New J. Chem., 2011, 35, 2314-2321.

36 B. F. Baggio, C. Vicente, S. Pelegrini, C. C. C. Plá, I. S. Brandt, M. A. Tumelero and A. A. Pasa, Morphology and Structure of Electrodeposited Prussian Blue and Prussian White Thin Films, Materials, 2019, 12, 1103.

37 T. Dumas, D. Guillaumont, P. Moisy, D. K. Shuh, T. Tyliszczak, P. L. Solari and C. D. Auwer, The electronic structure of f-element Prussian blue analogs determined by soft X-ray absorption spectroscopy, Chem. Commun., 2018, 54, 12206-12209. 